\title{
Characteristics and outcomes of fall-related open-globe injuries in pseudophakic patients
}

\author{
This article was published in the following Dove Press journal: \\ Clinical Ophthalmology \\ 27 February 2015 \\ Number of times this article has been viewed
}

\author{
Shaheen C Kavoussi' \\ Martin D Slade ${ }^{2}$ \\ Seth W Meskin' \\ Ron A Adelman' \\ 'Department of Ophthalmology \\ and Visual Science, ${ }^{2}$ Department \\ of Occupational and Environmental \\ Medicine, Yale University School \\ of Medicine, New Haven, CT, USA
}

Correspondence: Shaheen C Kavoussi Department of Ophthalmology, Yale University, 40 Temple Street, 3rd Floor, New Haven, CT 065I 0, USA

$\mathrm{Tel}+\mathrm{I} 2037852020$

Fax + I 203785 6I23

Email shaheen.kavoussi@yale.edu
Aim: We aimed to identify the characteristics and prognostic indicators of poor visual and anatomic outcome in pseudophakic patients with fall-related open-globe (OG) injuries. We used a case series design, for a total of 26 patients.

Methods: Charts of consecutive pseudophakic patients with fall-related OG injury at a single institution were reviewed. Demographics, ophthalmic history, circumstances of injury, initial best-corrected visual acuity (BCVA), examination findings, surgical interventions, and follow-up BCVA were tabulated for statistical analysis with unpaired $t$-tests and Fisher's exact tests.

Results: Nineteen patients $(73 \%)$ were women. Mean ( \pm standard deviation) age was 80.6 \pm 4.6 years (range: $61-97$ years). Initial BCVA was $<20 / 400$ in 24 of 25 patients $(96 \%)$. Mean ocular trauma score (OTS) was $38.54 \pm 10.95$. OTS was lower $(P=0.0017, P<0.0001$, and $P=0.0240)$ and wound size was larger $(P=0.0440,0.0145$, and 0.0026$)$ in patients with final BCVA $<20 / 40,<20 / 400$, and phthisis at final follow-up, respectively; compared to patients with $B C V A \geq 20 / 40,20 / 400$, and no phthisis at final follow-up, respectively. Final BCVA $<20 / 400$ was associated with $360^{\circ}$ subconjunctival hemorrhage $(\mathrm{SCH})$, retinal detachment, and proliferative vitreoretinopathy ( $P=0.0498,0.0181$, and 0.0310 , respectively). Total hyphema, intraocular lens (IOL) damage, and IOL expulsion were associated with needing multiple surgical interventions ( $P=0.0345, P<0.0001$, and $P=0.0023$, respectively).

Conclusion: Large wound size, low OTS, $360^{\circ} \mathrm{SCH}$, total hyphema, posterior injury, and IOL damage are common findings that are also prognostic of poor visual and anatomic outcome in pseudophakic patients with fall-related OG injuries. Ophthalmologists dealing primarily with geriatric populations should contribute to the discussion of fall risk.

Keywords: fall, injury, open globe, pseudophakia, trauma

\section{Introduction}

Falls are the most common cause of traumatic morbidity and mortality in the elderly and are responsible for hospitalization in up to one in three people over the age of 65 years. $^{1,2}$ Falls also account for $5 \%$ of ocular injuries, of which open-globe (OG) injuries pose the most serious threat to vision. According to the United States Eye Injury Registry, fall mechanism and age $>60$ years increased the likelihood of blindness, defined as best-corrected visual acuity (BCVA) worse than 20/200. . $^{3,4}$

In our anecdotal experience, visual outcomes are poor in pseudophakic geriatric patients with fall-related OG injuries, particularly with extracapsular cataract extraction (ECCE) wound dehiscence, but prognostic data are limited. Few reports have addressed geriatric and fall-related OG injuries in general., ${ }^{5,6}$ A report of phakic and pseudophakic geriatric OG injuries (all mechanisms) demonstrated worse initial and follow-up BCVA and lower ocular trauma score (OTS) compared to their younger counterparts. ${ }^{5}$ In a report of OG injuries resulting from falls in phakic and pseudophakic patients of 
all ages, fall-related OG injuries resulted in worse initial and postoperative BCVA, and they occurred more frequently in older patients than in the control database of OG injuries. ${ }^{6}$

The magnitude of the public health and economic consequences of fall-related ocular injuries will increase as the aging population grows. The aim of this study therefore was to investigate the characteristics, visual and surgical outcomes, and prognostic factors of fall-related OG injuries in pseudophakic patients.

\section{Methods}

The study protocol was approved by the Human Investigations Committee of the Yale University School of Medicine. A retrospective chart review was performed for all patients who presented to the Yale-New Haven Hospital with OG injury between January 1, 2003, and December 31, 2013. The hospital and outpatient records were reviewed for the selection of cases and tabulation of demographics, ophthalmic history, circumstances and mechanism of injury; BCVA and ocular examination findings at the time of injury; and surgical interventions and the follow-up BCVA and ocular examination findings. Fall-related OG injuries in pseudophakic patients with at least 6 months of follow-up after injury were identified for inclusion in the study.

OTS was calculated as described previously for each patient. ${ }^{7}$ We used unpaired $t$-tests to compare mean \pm standard deviation (SD) of the OTS between patients with 1) history of ECCE versus standard phacoemulsification (PE), 2) history of penetrating keratoplasty (PKP) versus no PKP, 3) final BCVA $\geq 20 / 40$ versus $<20 / 40,4$ ) final $B C V A \geq 20 / 400$ versus $<20 / 400$, and 5) phthisis at final follow-up versus no phthisis. Mean ( \pm SD) of wound size (in millimeters) was also compared among the aforementioned groups.

Fisher's exact tests were used to determine if significant associations existed between predictor variables and outcomes. Predictors were presence of layering hyphema (any size), total hyphema, $360^{\circ}$ subconjunctival hemorrhage ( $\mathrm{SCH}$ ), intraocular lens (IOL) damage, IOL expulsion, vitreous hemorrhage, retinal detachment $(\mathrm{RD})$, choroidal detachment or rupture, wound size $\geq 10 \mathrm{~mm}$, uveal prolapse, vitreous prolapse, corneal wound (Zone I), ${ }^{8}$ corneoscleral wound within $5 \mathrm{~mm}$ of the limbus (Zone II), corneoscleral wound extending $\geq 5 \mathrm{~mm}$ from the limbus (Zone III), future RD, and future proliferative vitreoretinopathy (PVR). Outcomes were final BCVA $\geq 20 / 40$, final BCVA $\geq 20 / 400$, final BCVA $<20 / 400$, no light perception at final follow-up, phthisis at final follow-up, $\geq 2$ surgeries needed during follow-up, and $\geq 3$ surgeries needed during follow-up. An odds ratio $>1$ (correlative) or $<1$ (inverse) with $P \leq 0.05$ was considered significant. Statistical analyses were performed using SAS 9.3.

\section{Results}

Inclusion criteria were met by 26 pseudophakic patients, 19 of whom $(73 \%)$ were women. Mean age $( \pm$ SD) was 80.6 \pm 4.6 years (range: $61-97$ years). Cataract surgery had been performed $4.6 \pm 3.4$ years (range: $1.5-14.0$ years) prior to the date of OG injury, and the procedure was $\mathrm{PE}$ in 16 patients (62\%) and ECCE in 10 patients (38\%). Ocular history also included PKP in four patients (15\%) and glaucoma surgery in two patients $(8 \%)$. Four patients $(15 \%)$ had dementia, and a majority of patients had at least one or a combination of cardiovascular comorbidities, including hypertension (88\%), diabetes (54\%), and coronary artery disease (38\%).

Falls occurred predominantly indoors and at home. The most common materials of impact were the floor, furniture, and sharp objects (Table 1). The left eye was injured in 14 of 26 cases (54\%). BCVA at the time of injury was $\leq 20 / 200$ in all patients and was $<20 / 400$ in 24 of 25 patients (96\%). One patient could not be tested for visual acuity due to profound dementia.

Hyphema was present in 22 patients ( $85 \%$ ), $77 \%$ of whom had $\geq 50 \%$ anterior chamber (AC) fill. All 26 patients had iris damage, including uveal prolapse in $85 \%$ of patients. Approximately half of the patients presented with $360^{\circ} \mathrm{SCH}$. Damage to the IOL included expulsed or dislocated IOLs in $58 \%$ of patients.

Adnexal injuries (periorbital ecchymosis and edema, facial laceration, and orbital fracture) and posterior injuries (vitreous hemorrhage, RD, and choroidal hemorrhage or detachment) were variably present at the time of globe rupture (Table 1). Wound location was predominant in Zones I and II; Zone III wounds occurred in six patients (23\%). There were no cases of intraocular foreign body.

Mean OTS was 38.54 \pm 10.95 . OTS was significantly lower in patients with 6-month and final BCVA $<20 / 40,<20 / 400$, and phthisis, compared to patients with $B C V A \geq 20 / 40,20 / 400$, and no phthisis, respectively $(P=0.0017, P<0.0001$, and $P=0.0240$; Table 2 and Figure 1). Wound size was significantly larger in the same categories $(P=0.0440,0.0145$, and 0.0026; Table 3 and Figure 2). There was no significant difference in OTS or wound size between patients with history of ECCE versus standard PE or between those with PKP versus no PKP. Times to presentation and primary repair were within 24 hours for 24 of 26 patients.

Mean final follow-up was $16.6 \pm 14.7$ months (range: 6-48 months). BCVA at 6 months and at final 
Table I Circumstances and characteristics of injury

\begin{tabular}{|c|c|}
\hline & $\mathbf{N}(\%)$ \\
\hline \multicolumn{2}{|l|}{ Location } \\
\hline Indoor & $18(69)$ \\
\hline Outdoor & $8(3 I)$ \\
\hline Home & $16(62)$ \\
\hline Outside the home/not specified & $10(38)$ \\
\hline \multicolumn{2}{|l|}{ Mechanism of injury } \\
\hline Rupture & $22(85)$ \\
\hline Penetration & $4(15)$ \\
\hline \multicolumn{2}{|l|}{ Material of impact } \\
\hline Floor/concrete/front porch & $13(50)$ \\
\hline Furniture* & $7(27)$ \\
\hline Other object** & $6(23)$ \\
\hline \multicolumn{2}{|l|}{ Presenting BCVA*** (25) } \\
\hline NLP & $4(16)$ \\
\hline $\mathrm{LP} / \mathrm{HM}$ & $17(68)$ \\
\hline $\mathrm{CF}$ & $3(12)$ \\
\hline $20 / 200$ & I (4) \\
\hline APD*** (13) & $6(46)$ \\
\hline Hyphema & $22(85)$ \\
\hline $100 \%$ AC fill & II (50) \\
\hline $50 \%-99 \%$ AC fill & $6(27)$ \\
\hline$<50 \%$ AC fill & $5(23)$ \\
\hline $360^{\circ} \mathrm{SCH}^{* * *}(24)$ & $13(54)$ \\
\hline Iris injury & $26(100)$ \\
\hline IOL damage & $15(58)$ \\
\hline Expulsed IOL & $11(73)$ \\
\hline Dislocated IOL & $4(27)$ \\
\hline Periorbital ecchymosis/edema & $19(73)$ \\
\hline Facial/lid laceration & $12(46)$ \\
\hline Orbital fracture & $7(27)^{\prime}$ \\
\hline $\mathrm{VH}$ & $21(8 I)$ \\
\hline RD & $12(46)$ \\
\hline PVR, delayed & $6(23)$ \\
\hline Choroidal detachment/rupture & $10(38)$ \\
\hline \multicolumn{2}{|l|}{ Wound location } \\
\hline Zone I & $18(69)$ \\
\hline Zone II & $17(65)$ \\
\hline Zone III & $6(23)$ \\
\hline \multicolumn{2}{|l|}{ Wound characteristics } \\
\hline$>10 \mathrm{~mm}$ & $14(54)$ \\
\hline Uveal prolapse & $22(85)$ \\
\hline Vitreous prolapse & $13(50)$ \\
\hline \multicolumn{2}{|l|}{ 6-month BCVA*** (25) } \\
\hline NLP/prosthesis & $6(24)$ \\
\hline $\mathrm{LP} / \mathrm{HM}$ & $5(20)$ \\
\hline $\mathrm{CF}$ & $7(28)$ \\
\hline$<20 / 40$ to $\geq 20 / 400$ & $3(12)$ \\
\hline$\geq 20 / 40$ & $4(16)$ \\
\hline \multicolumn{2}{|l|}{ Final BCVA *** $(25)$} \\
\hline NLP/prosthesis & $6(24)$ \\
\hline $\mathrm{LP} / \mathrm{HM}$ & $7(28)$ \\
\hline $\mathrm{CF}$ & $5(20)$ \\
\hline$<20 / 40$ to $\geq 20 / 400$ & $3(12)$ \\
\hline$\geq 20 / 40$ & $4(16)$ \\
\hline
\end{tabular}

Notes: *Furniture: table (4), night stand (2), and chair (I). **Other objects: walker, car door, cup, fork, thermostat. ***Numbers in parentheses denote total number of patients for whom the data were available if $<26$.

Abbreviations: AC, anterior chamber; APD, afferent pupillary defect; BCVA, best-corrected visual acuity; CF, count fingers; HM, hand motion; IOL, intraocular lens; LP, light perception; NLP, no light perception; PVR, proliferative vitreoretinopathy; RD, retinal detachment; $\mathrm{SCH}$, subconjunctival hemorrhage; $\mathrm{VH}$, vitreous hemorrhage. follow-up was $<20 / 400$ in 18 of 25 eyes (72\%). Twelve eyes $(46 \%)$ required $\geq 2$ surgeries after injury, including vitrectomy at a later date for cases that involved vitreous loss, nonclearing vitreous hemorrhage, or posterior injury. Seven eyes $(26 \%)$ developed phthisis, and enucleation was performed on one eye ( $2 \%)$. There were no cases of endophthalmitis, and all patients had received intravenous antibiotics at the time of OG repair.

Fisher's exact tests revealed decreased likelihood of 6-month and final BCVA $\geq 20 / 40$ in patients with wound size $\geq 10 \mathrm{~mm}$ and $\mathrm{RD}$ at the time of injury $(P=0.0491$, Table 4). Patients with $360^{\circ} \mathrm{SCH}$, wound size $\geq 10 \mathrm{~mm}$, RD at initial presentation, delayed RD, or delayed PVR were less likely to achieve BCVA $\geq 20 / 400$ at 6 months and at final follow-up $(P=0.0498, P=0.0181, P=0.0022, P<0.0001$, or $P=0.0097$, respectively; Table 4$)$. The number of required surgical interventions was more likely to be $\geq 2$ in patients who presented with total hyphema, IOL damage, and IOL expulsion $(P=0.0345, P<0.0001$, and $P=0.0023)$.

\section{Discussion}

While traumatic OG injuries are typically associated with young males, ${ }^{9,10}$ fall-related OG injury represents a demographically and clinically unique entity. Falls are the most common mechanism of OG injury in geriatric patients ${ }^{3}$ and in pseudophakic wound dehiscence. ${ }^{11}$ Women with osteoporosis and osteoarthritis face increased fall risk, and as was the case in our study, patients often have significant medical comorbidities, rendering the potential for the fall to be a preterminal event. ${ }^{6}$ Our cases also confirm prior reports of increased prevalence of fall-related OG injuries in elderly women, ${ }^{5,6,10,11}$ tendency for blunt rupture mechanism, ${ }^{6,10}$ and poor visual outcome..$^{6,10-12}$

Although ocular trauma in the domestic setting is underreported, ${ }^{9}$ our cases further suggest that fall-related $O G$ injuries are most commonly sustained at home. ${ }^{5}$ The surgical wound in pseudophakic patients appears to render the eye susceptible to blunt rupture. ${ }^{5,11}$ In a review of 63 patients with pseudophakic wound dehiscence caused by falls, blunt trauma, and motor vehicle accidents, history of standard PE was associated with better final BCVA compared to history of ECCE. ${ }^{11}$ In contrast, 14 of our 26 fall cases involved larger ECCE or PKP wounds, but neither of these entities was associated with decreased OTS, increased wound size, or decreased final BCVA compared to standard PE.

While the majority of injuries in the United States Eye Injury Registry demonstrate eventual recovery of functional visual acuity, ${ }^{3}$ visual acuity in our series was poor both at 
Table 2 Ocular trauma score at the time of injury

\begin{tabular}{|c|c|c|c|c|}
\hline & $\mathbf{N}$ & Mean & SD & $P$-value \\
\hline All patients & 26 & 38.54 & 10.95 & \\
\hline 6-month and final $B C V A \geq 20 / 40$ & 4 & 52.00 & 10.00 & 0.0017 \\
\hline 6-month and final BCVA $<20 / 40$ & 21 & 35.85 & 9.14 & \\
\hline 6-month and final $B C V A \geq 20 / 400$ & 7 & 51.29 & 7.87 & $<\mathbf{0 . 0 0 0 I}$ \\
\hline 6-month and final BCVA $<20 / 400$ & 18 & 33.69 & 7.01 & \\
\hline No phthisis & 18 & 41.82 & 10.99 & 0.0240 \\
\hline Phthisis at final follow-up & 7 & 30.57 & 5.63 & \\
\hline History of ECCE & 10 & 39.50 & 12.92 & 0.7261 \\
\hline History of standard PE & 16 & 37.86 & 9.76 & \\
\hline History of PKP & 4 & 36.50 & 7.77 & 0.4167 \\
\hline No PKP & 22 & 38.95 & 11.60 & \\
\hline
\end{tabular}

Note: Bold indicates significant values, $P<0.05$.

Abbreviations: BCVA, best-corrected visual acuity; ECCE, extracapsular cataract extraction; PE, phacoemulsification; PKP, penetrating keratoplasty; SD, standard deviation.

initial presentation and at final follow-up, including final BCVA $<20 / 400$ in $72 \%$ of eyes and hand motion vision or worse in more than half. Similarly, final BCVA was $<20 / 400$ in $84 \%$ of patients with fall-related OG injuries. ${ }^{6}$ In a study of geriatric OG injuries, lower OTS and worse initial and final visual acuity levels were noted in comparison to OG injuries in younger patients. ${ }^{5}$ In our patients, lower OTS, larger wound size, $360^{\circ} \mathrm{SCH}, \mathrm{RD}$, and $\mathrm{PVR}$ were predictive of poor visual outcome, while hyphema, iris injury, IOL damage, adnexal injury, vitreous hemorrhage, and wound location did not yield significant results. The average OTS in this pseudophakic fall population was 38.54 (SD: 10.95); thus, most patients were OTS Class 1 or 2 , with $>50 \%$ chance of final BCVA being light perception or worse. ${ }^{7}$ Concordantly, $52 \%$ of our patients had light perception or worse at 6 months and at final follow-up.

Posterior injuries were present in a majority of patients, while adnexal injuries (including periorbital ecchymosis or edema) and facial or eyelid laceration were important presenting signs and were more common in this series than in a population of all mechanisms of OG injury. ${ }^{13}$ There was $100 \%$ incidence of iris damage, which in conjunction with a limbal wound, predisposes the pseudophakic patient to hyphema and often bullous $\mathrm{SCH}$.

Enucleation and endophthalmitis have been uncommon outcomes in this population, likely due to blunt (rather than penetrating) OG injury mechanism and the absence of intraocular foreign body. ${ }^{5,6,14}$ However, phthisis tended

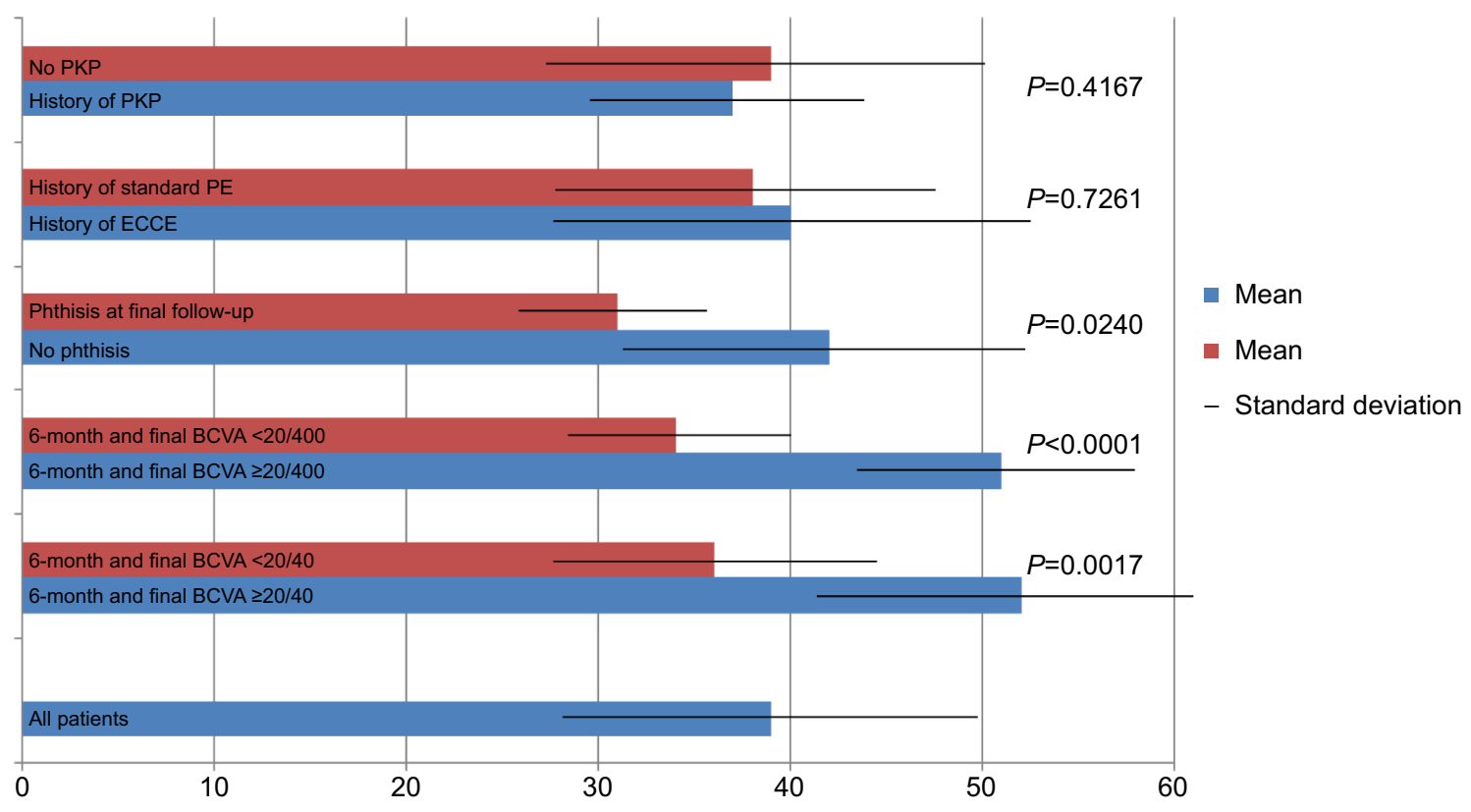

Figure I Ocular trauma score at the time of injury.

Abbreviations: BCVA, best-corrected visual acuity; ECCE, extracapsular cataract extraction; PE, phacoemulsification; PKP, penetrating keratoplasty. 
Table 3 Wound size $(\mathrm{mm})$ at the time of injury

\begin{tabular}{|c|c|c|c|c|}
\hline & $\mathbf{N}$ & Mean & SD & $P$-value \\
\hline All patients & 26 & 9.81 & 7.20 & \\
\hline 6-month and final $B C V A \geq 20 / 40$ & 4 & 3.63 & 1.70 & 0.0440 \\
\hline 6-month and final BCVA $<20 / 40$ & 21 & 11.47 & 7.20 & \\
\hline 6-month and final BCVA $\geq 20 / 400$ & 7 & 4.79 & 2.77 & 0.0145 \\
\hline 6-month and final BCVA $<20 / 400$ & 18 & 12.44 & 7.37 & \\
\hline No phthisis & 18 & 9.50 & 3.84 & 0.0026 \\
\hline Phthisis at final follow-up & 7 & 12.83 & 3.43 & \\
\hline History of ECCE & 10 & 9.50 & 3.84 & 0.8600 \\
\hline History of standard PE & 16 & 10.04 & 9.03 & \\
\hline History of PKP & 4 & 11.25 & 2.50 & 0.6718 \\
\hline No PKP & 22 & 9.53 & 7.83 & \\
\hline
\end{tabular}

Note: Bold indicates significant values, $P<0.05$.

Abbreviations: BCVA, best-corrected visual acuity; ECCE, extracapsular cataract extraction; PE, phacoemulsification; PKP, penetrating keratoplasty; SD, standard deviation.

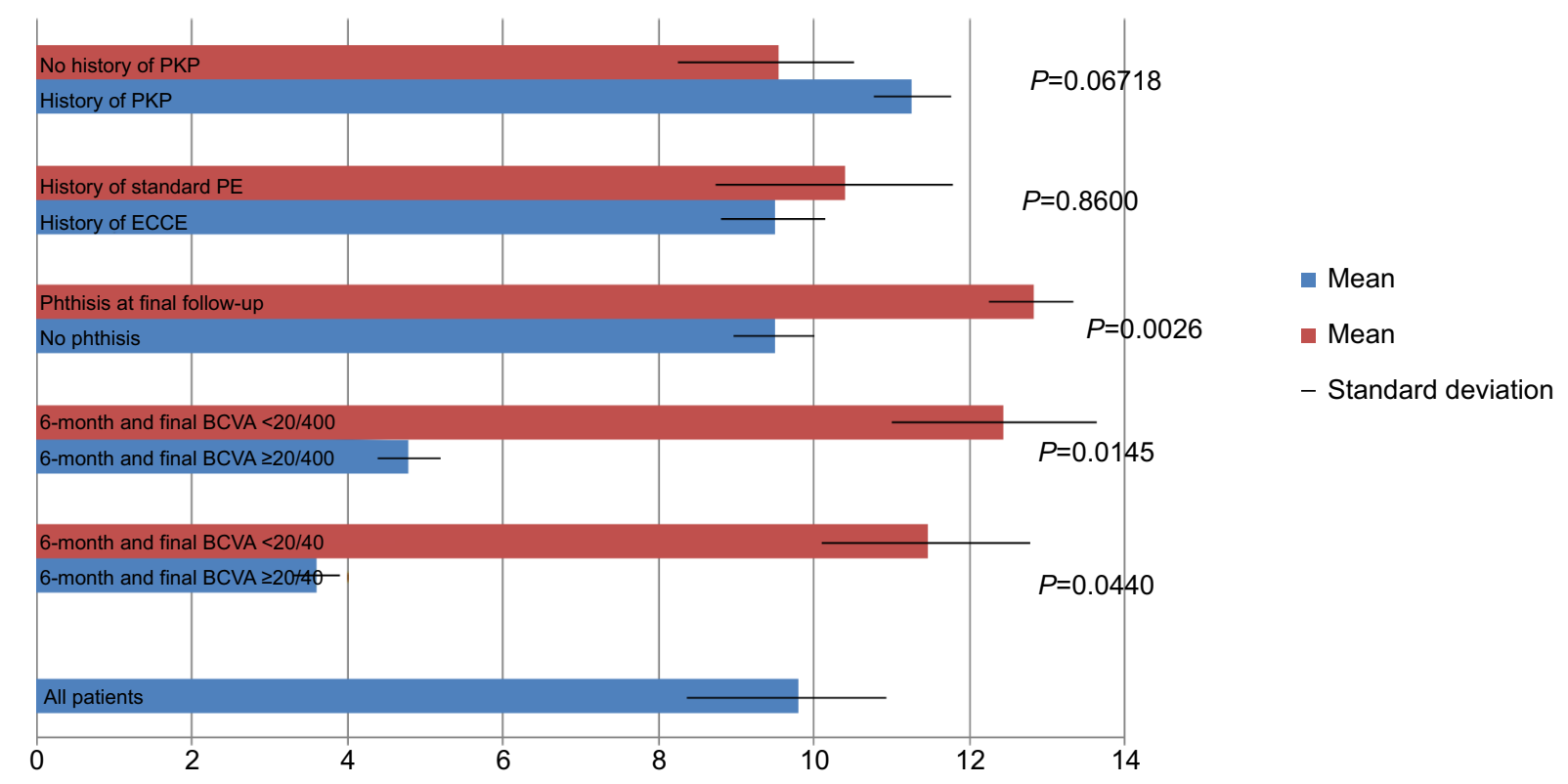

Figure 2 Wound size $(\mathrm{mm})$ at the time of injury.

Abbreviations: BCVA, best-corrected visual acuity; ECCE, extracapsular cataract extraction; PE, phacoemulsification; PKP, penetrating keratoplasty.

Table 4 Inverse correlation (odds ratio $<1$ ) of visual outcomes with initial or delayed ocular findings using Fisher's exact test

\begin{tabular}{lll}
\hline & P-value & Odds ratio \\
\hline 6-month and final BCVA $\geq 20 / 40$, by wound $\geq 10 \mathrm{~mm}$ & 0.049 I & 0.294 I \\
6-month and final $B C V A \geq 20 / 40$, by $R D$, initial presentation & 0.049 I & 0.294 I \\
6-month and final BCVA $\geq 20 / 400$, by $360^{\circ} \mathrm{SCH}$ & 0.0498 & 0.0800 \\
6-month and final BCVA $\geq 20 / 400$, by RD, initial presentation & 0.0022 & 0.2143 \\
6-month and final BCVA $\geq 20 / 400$, by wound $\geq 10 \mathrm{~mm}$ & $0.018 \mathrm{I}$ & 0.0545 \\
6-month and final BCVA $\geq 20 / 400$, by RD, initial or delayed & $<0.000 \mathrm{I}$ & 0.1429 \\
6-month and final BCVA $\geq 20 / 400$, by PVR, delayed & 0.0097 & 0.2500 \\
\hline
\end{tabular}

Abbreviations: BCVA, best-corrected visual acuity; PVR, proliferative vitreoretinopathy; RD, retinal detachment; SCH, subconjunctival hemorrhage. 
Table 5 Direct correlation (odds ratio $>$ I) of visual and surgical outcomes with initial or delayed ocular findings using Fisher's exact test

\begin{tabular}{lll}
\hline & P-value & Odds ratio \\
\hline 6-month and final BCVA $<20 / 400$, by $360^{\circ} \mathrm{SCH}$ & 0.0498 & 12.5000 \\
6-month and final BCVA $<20 / 400$, by RD, initial presentation & 0.0498 & 12.5000 \\
6-month and final BCVA $<20 / 400$, by RD, initial or delayed & $0.018 \mathrm{I}$ & 18.3333 \\
6-month and final BCVA $<20 / 400$, by PVR, delayed & 0.0310 & 3.0000 \\
$\geq 2$ surgeries needed, by hyphema I00\% & 0.0345 & 2.7500 \\
$\geq 2$ surgeries needed, by IOL damage & $<0.000 \mathrm{I}$ & 2.5000 \\
$\geq 2$ surgeries needed, by expulsed IOL & 0.0023 & 5.5000 \\
\hline
\end{tabular}

Abbreviations: BCVA, best-corrected visual acuity; IOL, intraocular lens; PVR, proliferative vitreoretinopathy; RD, retinal detachment; $\mathrm{SCH}$, subconjunctival hemorrhage.

to develop in patients with lower OTS and larger wound size. Approximately half of the patients required $\geq 2$ surgeries after injury, with IOL expulsion or dislocation and total hyphema being predictive factors. Limitations to this study include retrospective design and relatively small sample size due to the very specific nature of the injury and population. Furthermore, the presence of dementia in this population also limits the ability to obtain an accurate visual acuity.

In conclusion, fall-related OG injury in pseudophakic patients results in profound visual disability, with damage to multiple ocular structures. Wound size, OTS, hyphema, IOL damage, and posterior injury are important prognostic considerations. Despite vision being maximized in the pseudophakic population, the geriatric patient remains at risk for falls, particularly with previously addressed risk factors. Because visual loss is not a commonly discussed consequence of falls, it is incumbent upon the ophthalmologist, who deals primarily with the geriatric population, to contribute to the discussion of fall risk and direct the pseudophakic patient to appropriate educational resources.

\section{Acknowledgment}

This research was supported in part by an unrestricted departmental grant from the Research to Prevent Blindness, Inc.

\section{Disclosure}

The authors report no conflicts of interest in this work.

\section{References}

1. Sterling DA, O'Connor JA, Bonadies J. Geriatric falls: injury severity is high and disproportionate to mechanism. J Trauma. 2001;50(1): 116-119.

2. Sturnieks DL, St George R, Lord SR. Balance disorders in the elderly. Neurophysiol Clin. 2008;38(6):467-478.

3. May DR, Kuhn FP, Morris RE, et al. The epidemiology of serious eye injuries from the United States Eye Injury Registry. Graefes Arch Clin Exp Ophthalmol. 2000;238:153-157.

4. Kuhn F, Morris R, Witherspoon C, Mann L. Epidemiology of blinding trauma in the United States Eye Injury Registry. Ophthalmic Epidemiol. 2006;13:209-216

5. Andreoli MT, Andreoli CM. Geriatric traumatic open globe injuries. Ophthalmology. 2011;118(1):156-159.

6. Emami-Naeini P, Ragam A, Bauza AM, et al. Characteristics, outcomes, and prognostic indicators of fall-related open globe injuries. Retina. 2013;33(10):2075-2079.

7. Kuhn F, Maisiak R, Mann L, Mester V, Morris R, Witherspoon CD. The ocular trauma score (OTS). Ophthalmol Clin North Am. 2002;15: 163-165.

8. Pieramici DJ, Sternberg P Jr, Aaberg TM Sr, et al. A system for classifying mechanical injuries of the eye (globe). The Ocular Trauma Classification Group. Am J Ophthalmol. 1997;123:820-831.

9. Thylefors B. Epidemiological patterns of ocular trauma. Aust $N Z J$ Ophthalmol. 1992;20(2):95-98.

10. Koo L, Kapadia MK, Singh RP, Sheridan R, Hatton MP. Gender differences in etiology and outcome of open globe injuries. $J$ Trauma. 2005;59(1):175-178.

11. Kloek CE, Andreoli MT, Andreoli CM. Characteristics of traumatic cataract wound dehiscence. Am J Ophthalmol. 2011;152(2):229-233.

12. Chowers I, Anteby I, Ever-Hadani P, Frucht-Pery J. Traumatic wound dehiscence after cataract extraction. $J$ Cataract Refract Surg. 2001;27(8):1238-1242.

13. Hatton MP, Thakker MM, Ray S. Orbital and adnexal trauma associated with open-globe injuries. Ophthal Plast Reconstr Surg. 2002;18(6):458-461.

14. Thompson WS, Rubsamen PE, Flynn HW Jr, Schiffman J, Cousins SW. Endophthalmitis after penetrating trauma: risk factors and visual acuity outcomes. Ophthalmology. 1995;102:1696-1701.
Clinical Ophthalmology

\section{Publish your work in this journal}

Clinical Ophthalmology is an international, peer-reviewed journal covering all subspecialties within ophthalmology. Key topics include: Optometry; Visual science; Pharmacology and drug therapy in eye diseases; Basic Sciences; Primary and Secondary eye care; Patient Safety and Quality of Care Improvements. This journal is indexed on

\section{Dovepress}

PubMed Central and CAS, and is the official journal of The Society of Clinical Ophthalmology (SCO). The manuscript management system is completely online and includes a very quick and fair peer-review system, which is all easy to use. Visit http://www.dovepress.com/ testimonials.php to read real quotes from published authors. 